\title{
Mechanical and Thermomechanical Behavior of Sic/Si Compounds Subjected To Controlled Atmospheric Conditions
}

\author{
J.F. Gamarra-Delgado ${ }^{1}$ J.J. Paredes-Paz'1, V.C. Bringas-Rodríguez ${ }^{1}$, D.L. Mayta-Ponce1, \\ G.P. Rodríguez-Guillén' ${ }^{1}$ and F.A. Huamán-Mamani ${ }^{1}$
}

${ }^{1}$ Grupo de Investigación en Ciencia y Tecnología de Materiales, Departamento de Ciencias Naturales, Universidad Católica San Pablo, Arequipa, Perú

Urb. Campiña Paisajista, Quinta Vivanco s/n, Arequipa 04001, Perú

frank.gamarra23@gmail.com; janice.paredes@ucsp.edu.pe; veronicawnh@gmail.com; dlmayta@ucsp.edu.pe; gprodriguez@ucsp.edu.pe; fhuaman@ucsp.edu.pe

\begin{abstract}
Biomorphic SiC/Si compounds were fabricated from copaiba wood (Copaifera officinalis, natural wood native to Peru), by reactive infiltration of molten silicon in a porous carbon preform obtained by a controlled pyrolysis process of wood. Structural and microstructural characterization tests by X-ray diffraction and scanning electron microscopy, respectively, revealed, on the one hand, the presence of crystalline phases of $\mathrm{SiC}, \mathrm{Si}$ and $\mathrm{C}$, and on the other, the typical morphology of this type of material, which it consists of a continuous SiC scaffold with elongated channels in the direction of tree growth and the presence of residual $\mathrm{Si}$ and $\mathrm{C}$ located mainly in the porosities of the material. The mechanical behavior in uniaxial compression was also studied at a constant compression rate of 0.05 $\mathrm{mm} / \mathrm{min}$ and as a function of temperature (from ambient to $1400{ }^{\circ} \mathrm{C}$ ) and test atmosphere (ambient air, humid air, dry air, $\mathrm{Ar}, \mathrm{N}_{2}$ and reducing mixture $\left(95 \% \mathrm{Ar}+5 \% \mathrm{H}_{2}\right)$. The mechanical results were evaluated based on values of maximum stress and modulus of elasticity (stiffness), finding a clear reduction in the values of maximum stress and stiffness of the material when the samples passed of ambient test temperatures at $1400{ }^{\circ} \mathrm{C}$. On the other hand, mechanical tests in a controlled atmosphere were carried out at a constant temperature of $1100 \stackrel{\circ}{\circ}$ and the results showed that the mechanical behavior of the studied compounds is slightly influenced by the working atmosphere. Mechanical data found in the various test conditions will be an important support for the definition of the maximum allowable stress (considering the safety factor applied for a particular case) in the industrial application of the materials studied in this work.
\end{abstract}

Keywords: silicon carbide, mechanical resistance, controlled atmosphere, $\mathrm{SiC} / \mathrm{Si}$, copaiba, Copaifera officinalis
(C) Copyright 2020 Authors - This is an Open Access article published under the Creative Commons Attribution License terms (http://creativecommons.org/licenses/by/3.0). Unrestricted use, distribution, and reproduction in any medium are permitted, provided the original work is properly cited.

\section{Introduction}

The development of new engineering materials, mainly those that work in high temperature conditions, are currently in great demand. In this sense, the modern industry has seen in carbides an enormous potential to meet its highly demanding requirements regarding mechanical properties [1]. On the other hand, wood is a renewable resource with a unique cellular microstructure and whose architecture has been ranked by nature through the years. Wood has now become a very important precursor material for the development of new bio-inspired (biomorphic) materials, which take advantage of the good combination of mechanical resistance, toughness, rigidity and low density that most of the available timber species present. [2-9].

Most research work on carbides is currently focused on the fabrication and mechanical and functional characterization of biomorphic $\mathrm{SiC}$ and $\mathrm{SiC} / \mathrm{Si}$ obtained from cellulosic precursors [3][12]. Today there are several methods for obtaining biomorphic carbides, but the most studied method is that of reactive infiltration of metallic silicon in a porous carbon preform, which stands out among other methods for proposing a feasible, scalable, environmentally friendly methodology and energy saving [3]. The process of obtaining carbides from wood involves a first stage of 
pyrolysis the wood to obtain a carbon preform that is then infiltrated with metallic elements such as $\mathrm{Si}$, Ti, Ta, etc. The carbon preforms are obtained by a controlled thermal pyrolization process of the wood at temperatures above $800^{\circ} \mathrm{C}$ in an inert atmosphere (Ar, $\mathrm{N}_{2}$ ) [10][11], later the carbon preform is infiltrated with metallic elements considering a excess of these up to over $30 \%$ of the stoichiometric quantity necessary for the mass of carbon to infiltrate [12-16]

Biomorphic $\mathrm{SiC}$ and $\mathrm{SiC} / \mathrm{Si}$ applications are wide and depend on their mechanical properties and pore structure, the most outstanding applications include: high temperature filters for gas or liquid, catalyst support, energy storage materials, barriers thermal, anti-wear surfaces, etc. [17-21]

The mechanical properties of $\mathrm{SiC} / \mathrm{Si}$ compounds have been studied extensively [22-24], but mostly under ambient temperature and atmospheric conditions, however, only few studies have been directed at considering the atmosphere of work as a factor of great importance for the design of structures fabricated with $\mathrm{SiC} / \mathrm{Si}$. Therefore, the present study tries to show the effect of the change of working atmospheres in the maximum mechanical resistance and stiffness of SiC/Si composites.

\section{Materials and Methods}

$\mathrm{SiC} / \mathrm{Si}$ composite materials were fabricated by reactive infiltration of metallic silicon in porous carbon preforms. Several authors have previously reported the detailed fabrication methodology for these materials [13]. In this work copaiba wood was selected as the main raw material, this wood species is classified as high density basic wood and is native to the Peruvian jungle. Cubes of approximately $10 \mathrm{~mm}$ on each side were cut from the selected wood and then dried at 80 ${ }^{\circ} \mathrm{C}$, then they were conducted to a pyrolysis process in an inert atmosphere up to the maximum temperature of $900^{\circ} \mathrm{C}$ with an isotherm time of $30 \mathrm{~min}$. (Fig. 1 (a)).

The carbon preforms obtained after the pyrolysis were subjected to a reactive infiltration process under vacuum and at a maximum temperature of $1550{ }^{\circ} \mathrm{C}$ for 30 minutes with an excess of silicon of $50 \%$ with respect to the stoichiometric amount for the amount of carbon to be infiltrated (Fig . 1 (b)).
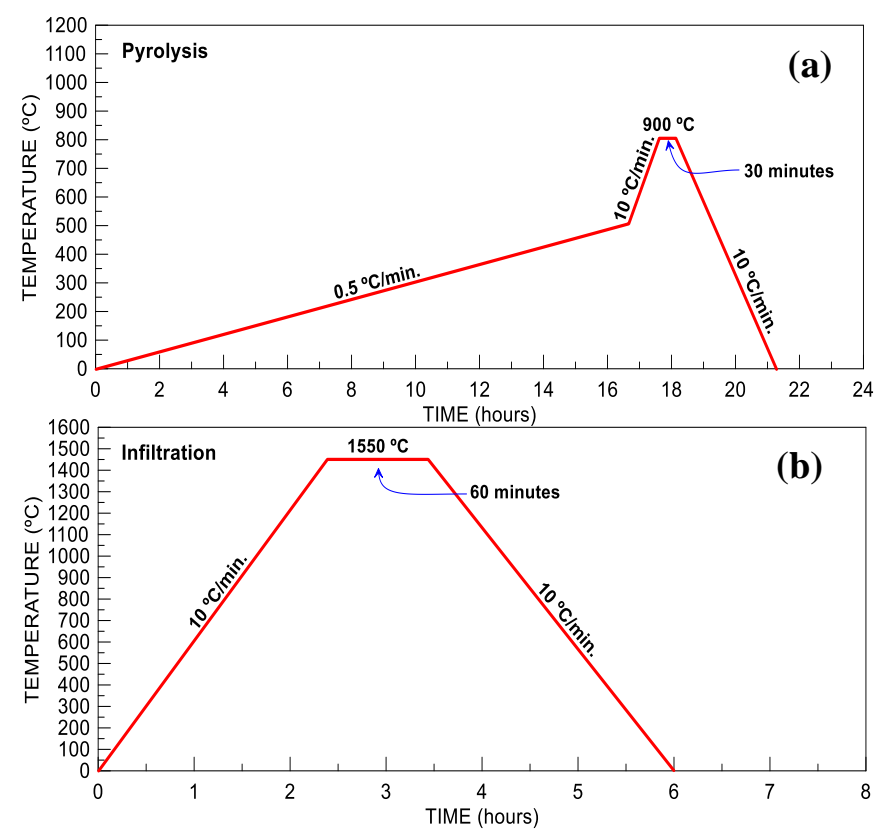

Fig. 1: Thermal profiles for the processes of (a) pyrolysis and (b) reactive infiltration.

The structural characterization of the carbon preforms and of the $\mathrm{SiC} / \mathrm{Si}$ compounds was carried out in an X-ray diffraction machine (Bruker, model D8 Endeavor, Germany) that has a $\mathrm{Cu}$ tube and $\mathrm{K} \alpha$ radiation (wavelength of $0.15405 \mathrm{~nm}$ ). All tests were performed in the $2 \theta$ scanning range of $10^{\circ}$ to $75^{\circ}$, with a step width of $0.02^{\circ}$ and tube conditions of $35 \mathrm{kV}$ and $40 \mathrm{~mA}$.

Microstructural characterization was performed on polished carbon and $\mathrm{SiC} / \mathrm{Si}$ surfaces using an AM SCOPE light microscope (50X - 500X ME320B-PZ, USA). Microstructural observations were made in reflection mode and on previously polished surfaces with grade 6 , 3 and 1 micron diamond paste (in that order).

The mechanical characterization was carried out in a universal testing machine (MICROTEST, model EM1/50/FR, Spain) that has three interchangeable chambers that cover the range of test temperatures between -30 and $1500{ }^{\circ} \mathrm{C}$ and has a hermetic system of control of atmospheres with which it is possible to carry out tests in environmental and non-ambient (inert, oxidizing or reducing) conditions. The mechanical tests were carried out in uniaxial compression at a constant compression rate of 0.05 $\mathrm{mm} / \mathrm{min}$ and at variable temperatures between ambient and $1400{ }^{\circ} \mathrm{C}$. In addition, with the aim of evaluating the effect of non-environmental conditions on the mechanical response of the studied materials, tests were carried out at a constant temperature of 
$1100{ }^{\circ} \mathrm{C}$ and in atmospheres of humid air, dry air, $\mathrm{Ar}, \mathrm{N}_{2}$ and reducing mixture $\left(95 \% \mathrm{Ar}+5 \% \mathrm{H}_{2}\right)$.

The samples used in the mechanical tests consisted of $5 \times 5 \times 10 \mathrm{~mm}$ parallelepipeds cut from larger samples with the help of a low speed precision cutter that has diamond edge discs. The force and displacement data obtained in the mechanical tests were converted to stress vs. strain graphs. The stressstrain curves allowed us to analyze and compare the values of maximum stress and moduli of elasticity of the materials studied under the various test conditions.

\section{Results and Discussion}

\subsection{Structural and Microstructural Characterization}

Fig. 2 shows the X-ray diffraction spectra for samples of carbon (Fig. 2 (a)) and of $\mathrm{SiC} / \mathrm{Si}$ compounds (Fig. 2 (b)). The diffraction peaks identified in the carbon sample reveal the presence of graphite, however, considering the shape of the baseline of the diffraction spectrum, the carbon obtained could be considered as a mainly amorphous material. On the other hand, the diffraction spectrum of the $\mathrm{SiC} / \mathrm{Si}$ compound confirms the presence of up to three crystalline phases: $\mathrm{SiC}$, carbon (graphite) and Si. The shape of the baseline indicates that the $\mathrm{SiC} / \mathrm{Si}$ compound after the infiltration process is completely crystalline and contains Si and C (graphite) residual.

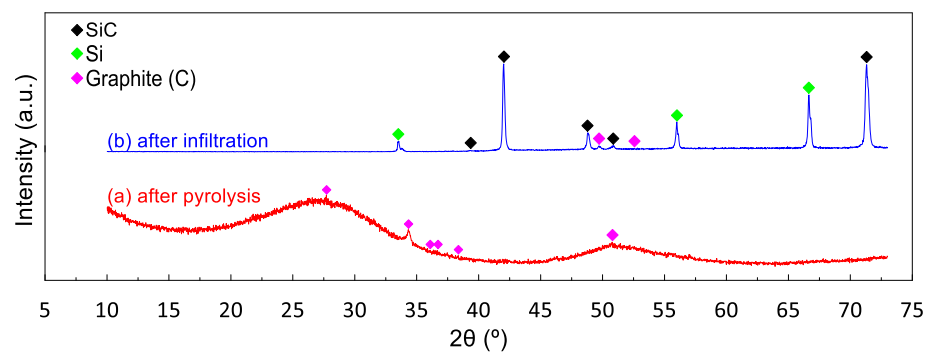

Fig. 2: Crystalline phases in (a) carbon preform and (b) $\mathrm{SiC} / \mathrm{Si}$.

Fig. 3 presents the morphology found on the surfaces of carbon (Fig. 3 (a)) and $\mathrm{SiC} / \mathrm{Si}$ compound (Fig. 3 (b)). Both microstructures are of the cross section (with respect to the growth direction of the tree) and are clearly defined. The carbon sample has a single phase of $\mathrm{C}$, with the presence of some rough or less rounded regions in darker contrast that would correspond to pores distributed throughout the area of the micrograph, and are also elongated in the growth direction of the tree. On the other hand, on the polished

surface of SiC/Si it was possible to observe up to four distinct phases: SiC (dark gray), Si (light gray), porosity (rounded black regions) and unreacted carbon (black regions no definite shape). The phases found microstructurally are in good agreement with the X-ray diffraction results presented in Fig. 2 of this work.
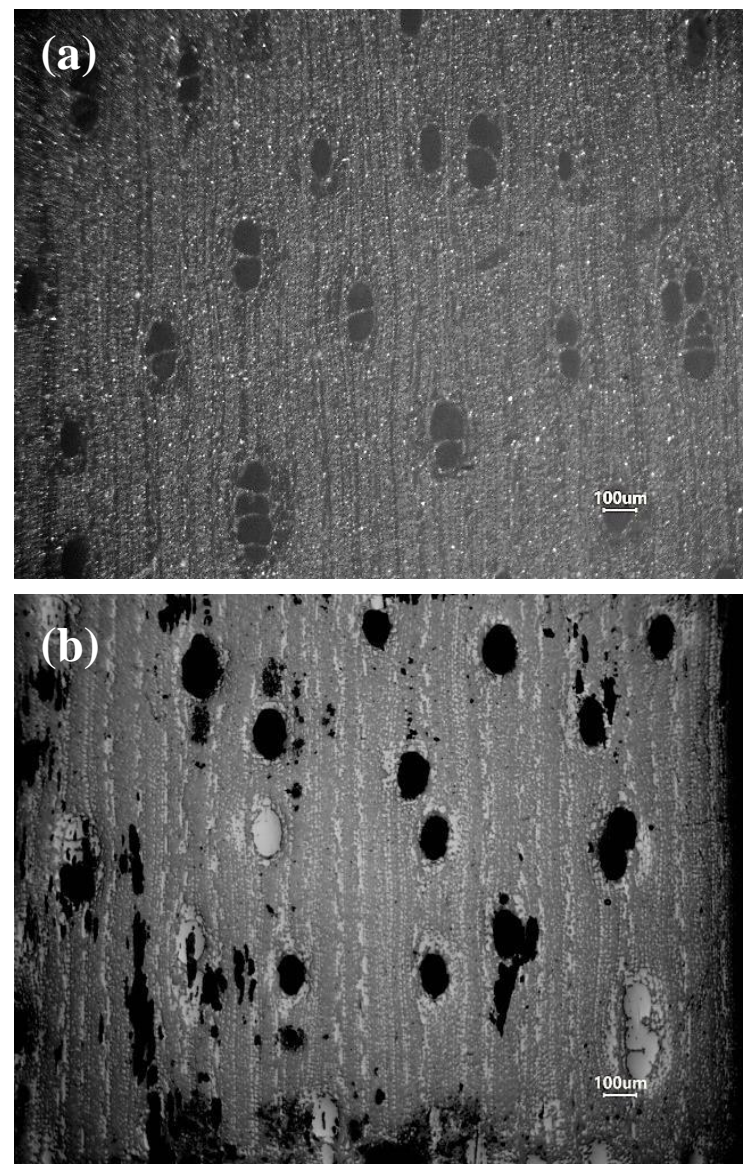

Fig. 3: Micrographs of cross sections of (a) carbon preform and (b) SiC/Si compound.

\subsection{Mechanical Characterization}

Fig. 4 presents stress vs. strain curves where a clear ratio of increase of the average maximum resistance is appreciated when increasing the amount of silicon in excess of 20 to $50 \%$ with respect to the stoichiometric molar ratio of the $\mathrm{SiC}$ molecule (Fig. 4 (ac)). On the other hand, a systematic reduction of the average maximum resistance can be seen when the test temperature increases from room temperature to 1400 ${ }^{\circ} \mathrm{C}$ in the compound with $50 \%$ excess silicon (Fig. 4 (cf)). 


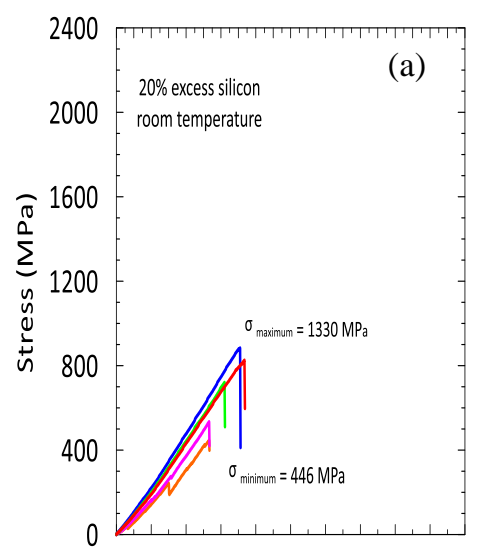

$\begin{array}{lllllll}0 & 2 & 4 & 6 & 8 & 101214161820\end{array}$ Strain (\%)

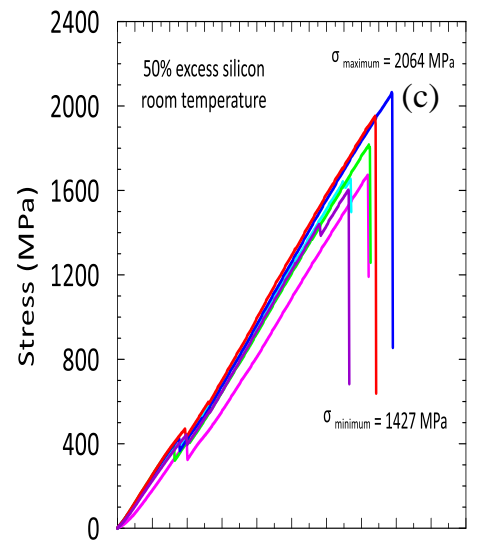

$0 \quad 2 \quad 4 \quad 6 \quad 8101214161820$ Strain $(\%)$

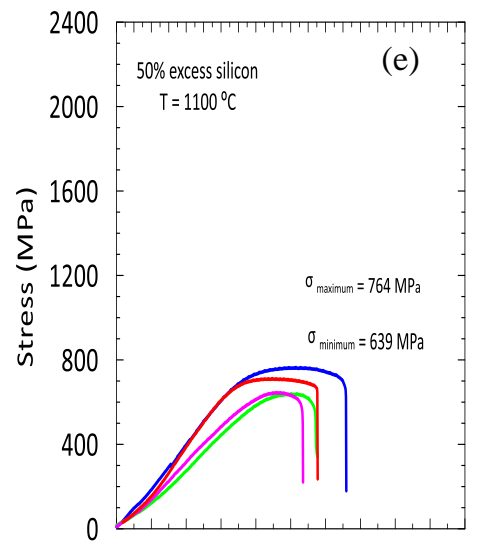

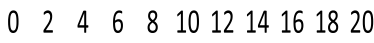
Strain $(\%)$
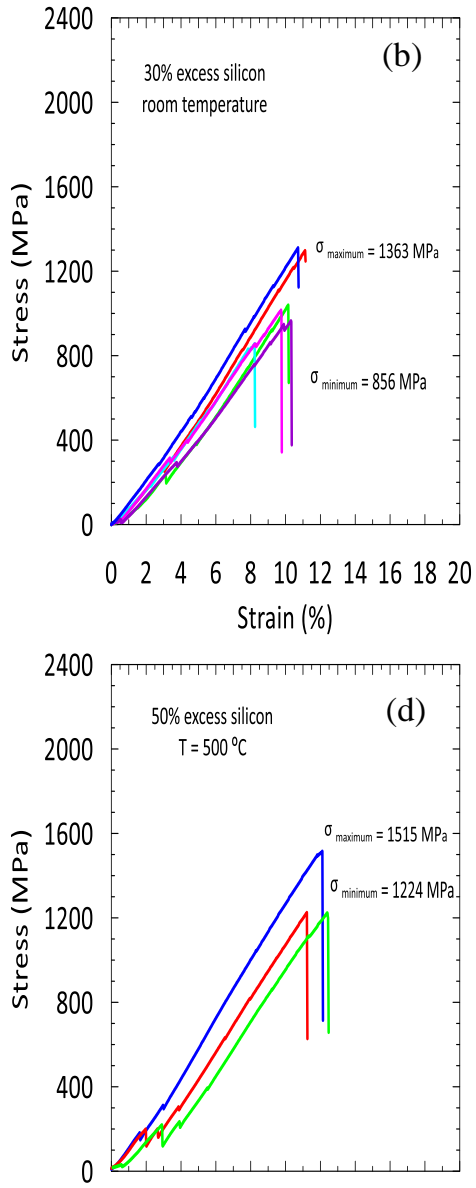

$0 \begin{array}{lllllll}0 & 4 & 6 & 8 & 101214161820\end{array}$ Strain $(\%)$

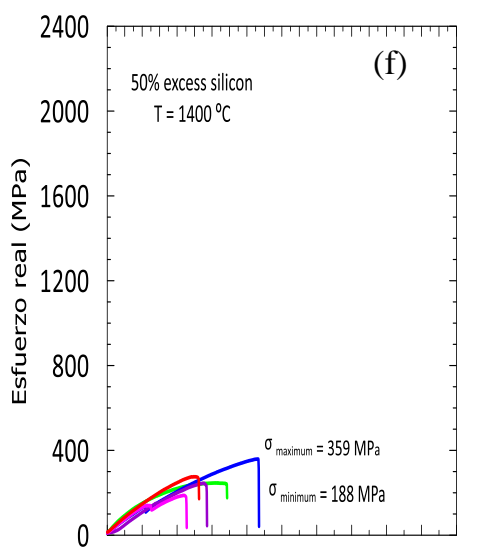

$\begin{array}{lllllllll}0 & 2 & 4 & 6 & 8 & 10 & 12 & 14161820\end{array}$ Deformación real (\%)

Fig. 4: Stress vs. strain curves for compounds with $20 \%$ (a), 30\% (b) and 50\% (c) of silicon in excess mechanically tested at room temperature (a-c), $500 \stackrel{\circ}{\circ} \mathrm{C}(\mathrm{d}), 1100 \stackrel{\circ}{\circ} \mathrm{C}(\mathrm{e})$ and $1400 \stackrel{\circ}{ } \mathrm{C}(\mathrm{f})$.
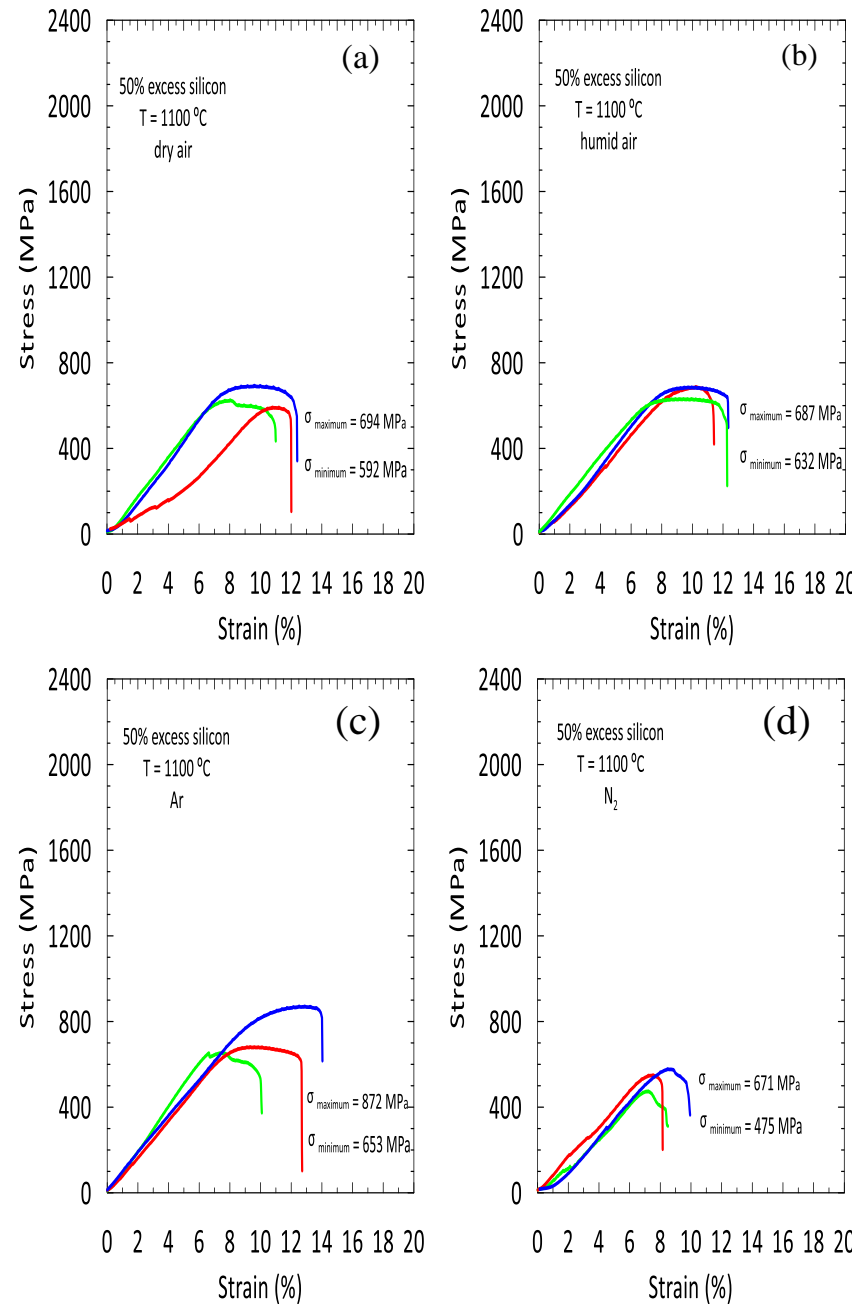

02468101214161820 Strain $(\%)$

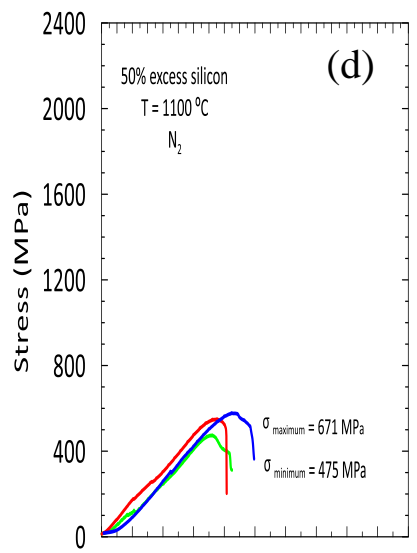

02468101214161820 Strain (\%)

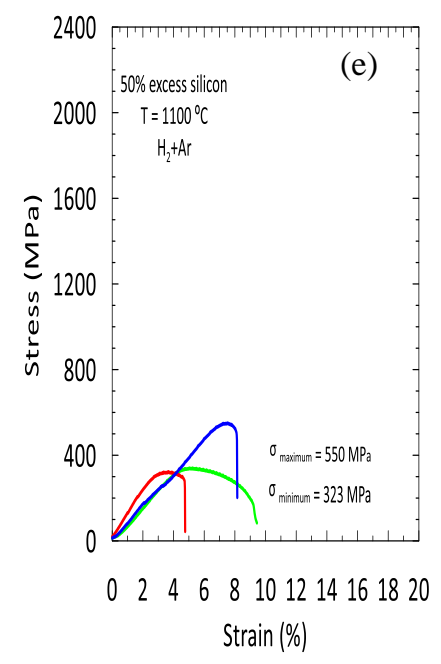

Fig. 5: Stress vs. strain curves for compounds with $50 \%$ silicon in excess mechanically tested at a temperature of $1100^{\circ} \mathrm{C}$ and in atmospheres of dry air (a), humid air (b), Ar (c), $\mathrm{N}_{2}$ (d) and a mixture of $\mathrm{H}_{2}(5 \%)+\operatorname{Ar}(95 \%)$ (e). 
Fig. 5 shows stress vs. strain curves for $\mathrm{SiC} / \mathrm{Si}$ compounds with $50 \%$ silicon in excess with respect to the stoichiometric composition of the $\mathrm{SiC}$ molecule. The tests were carried out in various types of atmospheres to verify the mechanical behavior (maximum resistance to compression and modulus of elasticity) of the materials studied under conditions in which they could work as part of industrial mechanical components. A greater sensitivity of the average maximum resistance in test atmospheres of $\mathrm{N}_{2}$ and $\mathrm{H}_{2}(5 \%)+\mathrm{Ar}(95 \%)$ could be appreciated.

Table 1 presents a summary of the data obtained for the mechanical resistance and moduli of elasticity maximum of $\mathrm{SiC} / \mathrm{Si}$ compounds evaluated in uniaxial compression and under variable conditions of temperature and atmosphere. It has been possible to verify a systematic reduction of the values of maximum stress and moduli of elasticity when the test temperature increases from room temperature to 1400 ${ }^{\circ} \mathrm{C}$. This result could be attributed to the presence of residual metallic silicon in the porosities of the $\mathrm{SiC}$ ceramic matrix. The metallic $\mathrm{Si}$ present in the $\mathrm{SiC} / \mathrm{Si}$ compound tends to soften with increasing test temperature, this effect being more evident at temperatures close to the melting point of Si. The effect of this softening translates into a systematic reduction in the overall stiffness of the $\mathrm{SiC} / \mathrm{Si}$ compound.

On the other hand, it has been possible to verify a slight relationship between the mechanical behavior of the $\mathrm{SiC} / \mathrm{Si}$ compound and the test atmosphere, which suggests that the change of working atmosphere should be considered in the engineering design of components or products that Include the material studied in this work.

Table 1: Mechanical data found for SiC/Si tested under variable conditions of temperature and atmosphere.

\begin{tabular}{cccc}
\hline atmosphere & $\begin{array}{c}\text { temperature } \\
\left({ }^{\circ} \mathrm{C}\right)\end{array}$ & $\sigma_{\text {máx. }}(\mathrm{MPa})$ & $\mathrm{E}(\mathrm{GPa})$ \\
\hline Air & $\mathrm{RT}$ & 2064 & 148 \\
Air & 500 & 1515 & 137 \\
Air & 1000 & 764 & 107 \\
Air & 1400 & 359 & 57 \\
Dry air & 1100 & 694 & 101 \\
Humid air & 1100 & 687 & 96 \\
$\mathrm{~N}_{2}$ & 1100 & 671 & 84 \\
Ar & 1100 & 872 & 105 \\
$\mathrm{H}_{2}(5 \%)+$ Ar & 1100 & 550 & 114 \\
$(95 \%)$ & & & \\
\hline RT: room temperature &
\end{tabular}

Fig. 6. shows the upper and lower limits found for the data set of maximum stresses and moduli of elasticity of $\mathrm{SiC} / \mathrm{Si}$ compounds under conditions of variable temperature and test atmosphere. Fig. 6 (a) and 6 (b) show the influence of the test temperature on the average maximum stress and modulus of elasticity, respectively. A lower dispersion of values can be seen when the test is carried out at $1400{ }^{\circ} \mathrm{C}$, this observation could suggest that at temperatures of $1400{ }^{\circ} \mathrm{C}$ the $\mathrm{Si}$ present in the compound contributes minimally to the overall mechanical response of the compound (being close to its melting point), which can be seen more clearly in Fig. 6 (a) In this scenario, only the mechanical response mechanisms of the $\mathrm{SiC}$ ceramic matrix take on importance for data analysis.
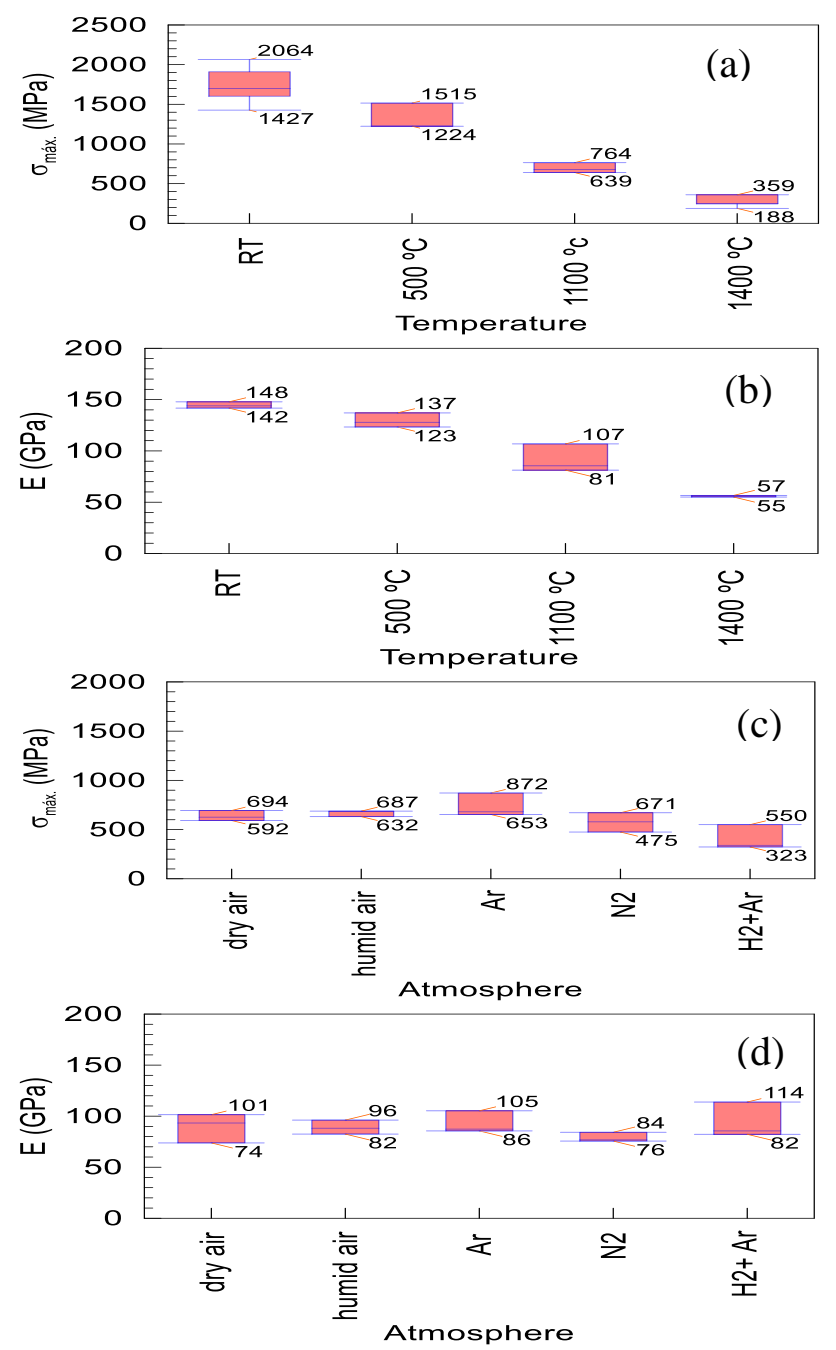

Fig. 6: Comparison of data of maximum stress and moduli of elasticity as a function of temperature and atmosphere for $\mathrm{SiC} / \mathrm{Si}$ compounds. 
Another important aspect that deserves to be analyzed correctly can be seen in the tests at room temperature (RT) of Figs. 6 (a) and 6 (b), where the values found for the maximum stress are widely dispersed between 1427 and $2064 \mathrm{MPa}$, while the values for the modulus of elasticity only have a slight dispersion between 142 and $148 \mathrm{MPa}$. In this regard, it could be suggested that the dispersion of the maximum stress values is due to the fact that the appearance and propagation of cracks in the ceramic matrix (responsible for the maximum stress of the material) is variable and occurs at stresses above the proportional limit. . For its part, the modulus of elasticity has little dispersion at room temperature because this property is measured only in the elastic range before the limit of proportionality (before cracks appear).

Figs. 6 (c) and 6 (d) show the upper and lower limits for all the data found for maximum stress and moduli of elasticity of $\mathrm{SiC} / \mathrm{Si}$ compounds tested in variable atmospheres. In this regard, previously we must mention that this group of tests were carried out at a constant temperature of $1100{ }^{\circ} \mathrm{C}$, since it was previously possible to confirm that at that temperature the material exhibited a completely fragile behavior and in this way only the test atmosphere could influence the mechanical behavior of the studied materials. The results found showed that the $\mathrm{SiC} / \mathrm{Si}$ compounds were very mechanically stable in humid air and dry air atmospheres, with respect to their maximum stress, but under nitrogen and reducing atmospheric (95\% Ar + $5 \% \mathrm{H}_{2}$ ) conditions, their maximum stress was slightly reduced. The results of maximum stress in an inert atmosphere of Ar were on average the highest, this result could suggest that when the $\mathrm{SiC} / \mathrm{Si}$ compound is in an inert environment it does not undergo any chemical change leading to the mechanical instability of the material. In the other test atmospheres it is possible that chemical changes occur that produce an effect on the final mechanical response of the materials, hence the importance of evaluating the dispersion of data to be able to suggest permissible design effort from the application that can be used give the studied material.

The comparative graph of the modulus of elasticity (E) as a function of the test atmosphere shown in Fig. 6 (d)) reveals that there is no clear or direct relationship between the test atmosphere and the stiffness of the materials studied in this work. Therefore, it could be suggested that the stiffness of the material is stable in various working environments.

\section{Conclusions}

$\mathrm{SiC} / \mathrm{Si}$ compounds have been successfully fabricated from copaiba wood, following procedures established in the literature for wood pyrolysis in an inert atmosphere followed by reactive infiltration of metallic silicon in carbon preforms.

$\mathrm{X}$-ray diffraction studies confirmed the presence of a mostly amorphous phase in samples of pyrolyzed wood (carbon preform) with low energy graphite peaks. On the other hand, it was found that the $\mathrm{SiC} / \mathrm{Si}$ compounds obtained after the reactive infiltration process were completely crystalline with the presence of diffraction peaks of $\mathrm{SiC}, \mathrm{Si}$ and $\mathrm{C}$ (graphite).

The microstructural studies were in good agreement with the data found in the DRX studies, showing a single homogeneous phase of carbon in the samples of pyrolyzed wood (with morphology similar to that of the cellulosic precursor) and four phases in the $\mathrm{SiC} / \mathrm{Si}$ compounds. : SiC (dark gray), Si (light gray), residual carbon (black without defined shape) and pores (black with rounded shape).

Uniaxial compression studies showed a clear influence of the maximum stress and modulus of elasticity with the test temperature. It was found that as the test temperature increased, the studied materials became less rigid and presented less maximum stress. It is suggested that these results are due to the progressive softening of the remaining $\mathrm{Si}$ as the test temperature near the silicon melting point increases.

The mechanical data found in the controlled atmosphere tests showed that the studied materials are sensitive (respect to their maximum stress) to the change in working atmosphere, mainly in nitrogen and reducing mixture atmospheres $\left(95 \% \mathrm{Ar}+5 \% \mathrm{H}_{2}\right)$. However, changes in atmosphere do not have a definitive effect on the stiffness of the materials studied. Both, the maximum stress and stiffness of the materials studied under conditions of variable temperatures and atmospheres must be considered to define the allowable stress of these materials in their probable industrial application.

\section{Acknowledgements}

This work was financed by the project Concytec Banco Mundial, through its executing unit the Fondo Nacional de Desarrollo Científico, Tecnológico y de Innovación Tecnológica (Fondecyt) within the framework of call E041-01 with contract $\mathrm{N}^{\circ} 36-2018$ FONDECYT-BM-IADT-AV and was executed in the laboratories of the Universidad Católica San Pablo. 


\section{References}

[1] Li, F., Liu, J., Huang, X., Zhang, G., "Porous Ultra-High Temperature Ceramics: Preparation, Structure and Properties", J. of the Chin. Ceram. Soc., 46(12), pp. 1669-1684, 2018.

[2] Parlett, C.M.A., Wilson, K., Lee, A.F., "Hierarchical porous materials: Catalytic applications", Chem. Soc. Rev., 42 (9), pp. 3876-3893, 2013.

[3] Min Yu, Guo-jun Zhang, Theo Saunders, "Woodderived ultra-high temperature carbides and their composites: A review", Ceram. Inter., vol. 46, issue 5, pp. 5536-5547, 2020

[4] M.P. Wolcott, K. Englund, "A technology review of wood-plastic composites", in 33rd Inter. Part. board/composite Mat. Sym. Proc., 1999.

[5] C.L. Huang, H. Lindström, R. Nakada, J. Ralston, "Cell wall structure and wood properties determined by acoustics-a selective review", Holz Roh Werkst, 61(5), pp. 321-335, 2003.

[6] R. Astley, J. Harrington, K. Stol, "Mechanical modelling of wood microstructure, an engineering approach", Trans. Inst. Prof. Eng. N. Z. Electr. Mech. Chem. Eng. Sect., 24(1), pp. 21, 1997.

[7] S.C. Mayo, F. Chen, R. Evans, "Micron-scale 3D imaging of wood and plant microstructure using high-resolution X-ray phase-contrast microtomography", J. of Struc. Biol., vol. 171, issue 2, pp. 182-188, 2010.

[8] D.E. Kretschmann, "Mechanical properties of wood Environments”, 5, pp. 34, 2010.

[9] Jianwei Song, Chaoji Chen, Shuze Zhu, Mingwei Zhu, Jiaqi Dai, Upamanyu Ray, Yiju Li, Yudi Kuang, Yongfeng Li, Nelson Quispe, Yonggang Yao, Amy Gong, Ulrich H. Leiste, Hugh A. Bruck, J. Y. Zhu, Azhar Vellore, Heng Li, Marilyn L. Minus, Zheng Jia, Ashlie Martini, Teng Li, Liangbing $\mathrm{Hu}$ "Processing bulk natural wood into a highperformance structural material" Nat., 554 (7691), pp. 224, 2018.

[10] C.E. Byrne, D.C. Nagle, "Carbonized wood monoliths Characterization” Carbon, 35 (2), pp. 267-273, 1997.

[11] C.E. Byrne, D.C. Nagle, "Carbonization of wood for advanced materials applications", Carbon, 35(2), pp. 259-266, 1997.

[12] P. Greil, T. Lifka, A. Kaindl, "Biomorphic cellular silicon carbide ceramics from wood: II. Mechanical properties", J. Eur. Ceram. Soc., 18(14), pp. 1975-1983, 1998.
[13] P. Greil, T. Lifka, A. Kaindl, "Biomorphic cellular silicon carbide ceramics from wood: I. Processing and microstructure", J. Eur. Ceram. Soc., 18(14), pp.1961-1973, 1998.

[14] Dong-Woo Shin, Sam Shik Park, Yong-Ho Choa, Koichi Niihara, "Silicon/silicon carbide composites fabricated by infiltration of a silicon melt into charcoal", J. Am. Ceram. Soc., 82(11), pp. 3251-3253, 1999.

[15] C. Zollfrank, H. Sieber, "Microstructure and phase morphology of wood derived biomorphous SiSiCceramics", J. Eur. Ceram. Soc., 24(2), pp. 495-506, 2004.

[16] F.M. Varela-Feria, J. Martínez-Fernández, A.R de Arellano-López, M. Singh, "Low density biomorphic silicon carbide: microstructure and mechanical properties", J. Eur. Ceram. Soc., 22(14), pp.2719-2725, 2002.

[17] K. E. Pappacena, K. T. Faber H. Wang, W. D. Porter, "Thermal conductivity of porous silicon carbide derived from wood precursors", J. Am. Ceram. Soc., 90(9), pp. 2855-2862, 2007.

[18] P. González, J. Serra, S. Liste, S. Chiussi, B. León, M. Pérez-Amor, J. Martínez-Fernández, A.R. de Arellano-López, F.M. Varela-Feria, "New biomorphic $\mathrm{SiC}$ ceramics coated with bioactive glass for biomedical applications", Biom., 24 (26), pp. 4827-4832, 2003.

[19] M.P. Orihuela, A. Gómez-Martín, J.A. BecerraVillanueva, J. Ramírez-Rico, J. MartínezFernández, "Comportamiento del SiC biomórfico como filtro de partículas en motores diésel de automoción" in LV Congr Nac La Soc Española Cerámica y Vidrio, 2016.

[20] M. Pilar Orihuela, Aurora Gómez-Martín, José A. Becerra, Ricardo Chacartegui, Joaquín RamírezRico, "Performance of biomorphic Silicon Carbide as particulate filter in diesel boilers", J. of Env. Man., vol. 203, part 3, pp. 907-919, 2017.

[21] A. Gómez-Martín, M.P. Orihuela, J. Ramírez-Rico, R. Chacartegui, J. Martínez-Fernández, “Thermal conductivity of porous biomorphic SiC derived from wood precursors", Ceram. Inter., vol. 42, issue 14, pp. 16220-16229, 2016.

[22] Nataliya D. Shcherban, "Review on synthesis, structure, physical and chemical properties and functional characteristics of porous silicon carbide", J. of Ind. and Eng. Chem., vol. 50, pp. 1528, 2017. 
[23] M.A. Bautista, J. Quispe Cancapa, J. Martinez Fernandez, M.A. Rodríguez, M. Singh, "Microstructural and mechanical evaluation of porous biomorphic silicon carbide for high temperature filtering applications", J. of the Eur. Ceram. Soc., vol. 31, issue 7, pp. 1325-1332, 2011.

[24] Zili Yan, Jie Liu, Jianchun Zhang, Tian Ma, Zhengcao $\mathrm{Li}$, "Biomorphic silicon/silicon carbide ceramics from birch powder", Ceram. Inter., vol. 37, issue 3, pp.725-730, 2011. 